
Not for reproduction, distribution or commercial use.

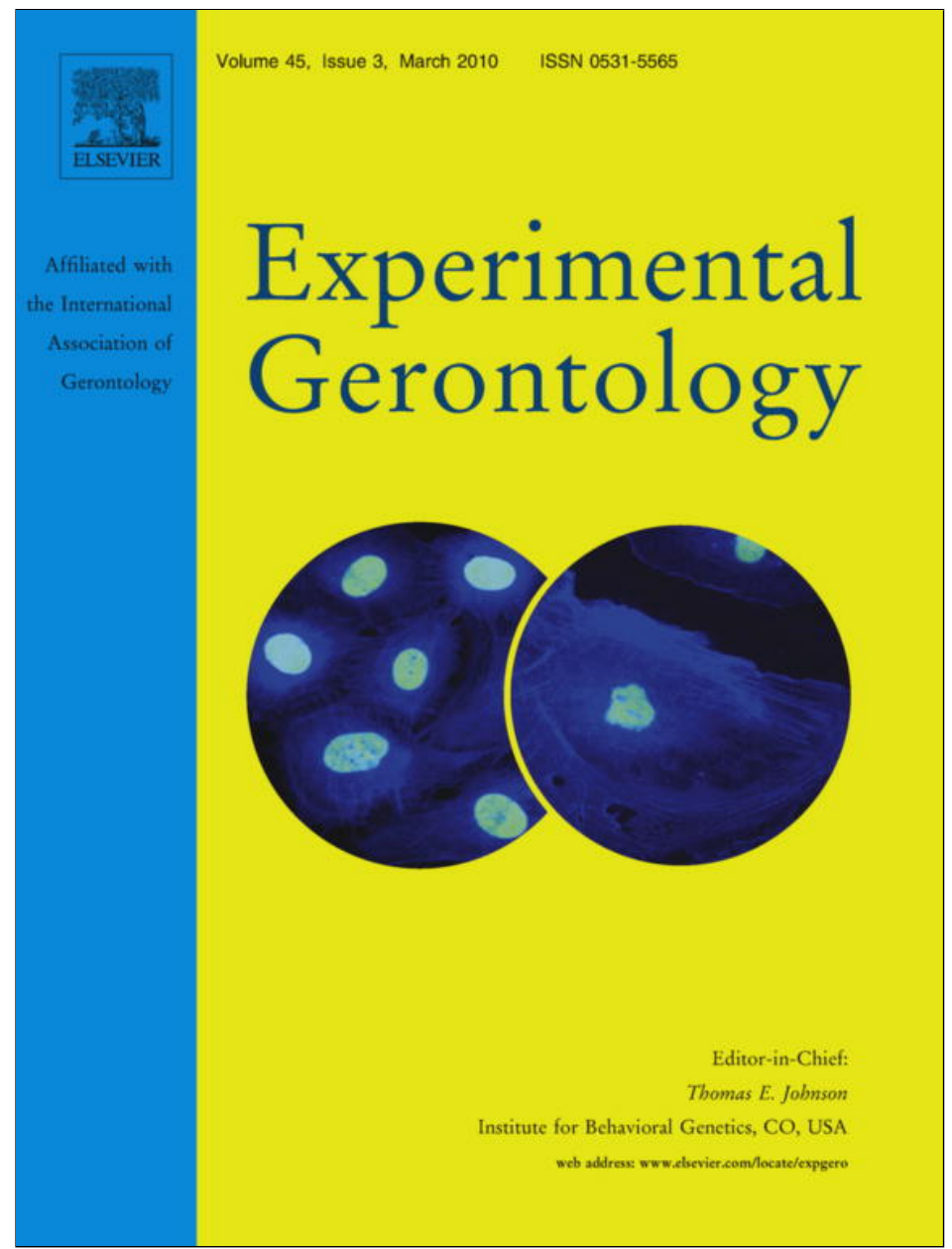

This article appeared in a journal published by Elsevier. The attached copy is furnished to the author for internal non-commercial research and education use, including for instruction at the authors institution and sharing with colleagues.

Other uses, including reproduction and distribution, or selling or licensing copies, or posting to personal, institutional or third party websites are prohibited.

In most cases authors are permitted to post their version of the article (e.g. in Word or Tex form) to their personal website or institutional repository. Authors requiring further information regarding Elsevier's archiving and manuscript policies are encouraged to visit:

http://www.elsevier.com/copyright 


\title{
Transcriptomic biomarkers of human ageing in peripheral blood mononuclear cell total RNA
}

\author{
Thi Kim Duy Vo ${ }^{a}$, Patrice Godard ${ }^{a}$, Marie de Saint-Hubert ${ }^{b}$, Gabriel Morrhaye ${ }^{c}$, Emilie Bauwens ${ }^{a}$, \\ Florence Debacq-Chainiaux ${ }^{\mathrm{a}}$, Youri Glupczynski ${ }^{\mathrm{b}}$, Christian Swine ${ }^{\mathrm{b}}$, Vincent Geenen ${ }^{\mathrm{c}}$, \\ Henri J. Martens ${ }^{c}$, Olivier Toussaint ${ }^{\mathrm{a}, *}$ \\ a Unit of Research on Cellular Biology, University of Namur (FUNDP), Rue de Bruxelles 61, B-5000 Namur, Belgium \\ ${ }^{\mathrm{b}}$ Department of Geriatrics University Hospital of Mont-Godinne, Université Catholique de Louvain (UCL), Av Dr G. Therasse, 1 B-5530 Yvoir, Belgium \\ ${ }^{\mathrm{c}}$ University of Liege, Center of Immunology, Laboratory of Immunoendocrinology, Institute of Pathology CHU-B23, B-4000 Liege-Sart Tilman, Belgium
}

\section{A R T I C L E I N F O}

\section{Article history:}

Received 16 September 2009

Received in revised form 25 November 2009

Accepted 1 December 2009

Available online 6 December 2009

\section{Keywords:}

Ageing

PBMC

Gene expression

Biomarker

Immunosenescence

Oxidative stress

cDNA array

\begin{abstract}
A B S T R A C T
Age-related changes of gene expression contribute to the physiological alteration observed with human ageing. Herein, the abundance of a selection of 148 transcripts involved in immunosenescence and stress response was compared in total RNA of PBMC of healthy young to middle-age probands ( $35.0 \pm 6.5$ year old) and healthy old probands ( $82.5 \pm 6.8$ year old). This study provides a list of 16 differentially abundant transcripts species in the healthy old probands. Thus, these changes of abundance can be considered as easily accessible biomarkers of ageing. Some of these differential abundances like CD28, CD69, LCK (decreased abundance in old subjects), CD86, Cathepsin D, H and S (increased abundance in old subjects) might explain biochemical and cytochemical changes observed at the protein level in the immune system and thus might correspond to regulatory processes affecting the ageing process. Indeed these changes reflect the low-grade pro-inflammatory status observed in old persons and suggest a hypo-responsiveness of T-cells together with an increase in antigen presentation potential. In addition, among the differentially abundant transcripts were transcripts involved in the oxidative stress response HMOX1 and HSPA6 mRNAs were found as more abundant in PBMC from elderly subjects.
\end{abstract}

(c) 2009 Elsevier Inc. All rights reserved.

\section{Introduction}

Ageing is defined as a progressive deterioration of biological functions (Farooqui and Farooqui, 2009) with progressive decreases of physiological capacity, reduced ability to cope with environmental stimuli, dysregulated inflammatory responses and changes in the immune response. Immunosenescence refers to the gradual age-related deterioration or modification of the immune system (Thoman and Weigle, 1989). Age-related changes of the immune system have been observed in both innate and acquired immunity (Huppert et al., 1998; Plackett et al., 2004). The effect of ageing on the functional capacity of T-cells was the most extensively studied. Some of the age-dependent biological changes that contribute to the onset of immunosenescence could result from the organism adaptation to the continuous challenge of adap-

Abbreviations: APC, antigen presenting cell; cDNA, complementary deoxyribonucleic acid; IFN- $\gamma$, interferon- $\gamma$; IL-10, interleukin-10; PBMC, peripheral blood mononuclear cells; RT-qPCR, retrotranscription quantitative polymerase chain reaction.

* Corresponding author. Tel.: +32 817241 32; fax: +32 81724135 .

E-mail address: olivier.toussaint@fundp.ac.be (O. Toussaint). tation to the environment. Ageing is accompanied by a chronic pro-inflammatory state, due to continuous antigenic stress that impinges upon innate immunity, throughout life, and has potential implications for the onset of inflammatory diseases (Vasto et al., 2007).

Transcriptomic profilings have been performed to study the effect of ageing on the regulation of gene expression in several cell types or organs (Galvin and Ginsberg, 2005; Vasto et al., 2007). Another purpose of gene expression profilings is to identify biomarkers that can be used later to better distinguish the state of physiological ageing of humans as opposed to their chronological ageing.

Herein, we developed a low-density DNA array to study the relative abundance of a selection of 148 transcripts species involved in immunosenescence, inflammation, stress response, cell or apoptosis regulation. The selection of 32 transcripts species involved in T-cell senescence was made upon survey of the literature. The selection of 116 transcripts species associated with stress response and cell senescence was also made according to literature survey. In addition, experimental work on cell senescence allowed to disregard transcripts for which differential abundance was not found in several in vitro and in vivo experimental models (Borlon et al., 
2008a,b; de Magalhaes et al., 2004; Debacq-Chainiaux et al., 2005, 2008; Pascal et al., 2005; Zdanov et al., 2006). The reliability of the particular technology used herein was demonstrated previously in cell senescence-related studies and other biological models such as hepatic toxicology, adipocyte differentiation and oncology (de Longueville et al., 2002; Gillet et al., 2004; Vankoningsloo et al., 2006). Inter- and intraplatform reproducibility of gene expression measurements was demonstrated with this technology (Patterson et al., 2006; Shi et al., 2006). Numerous verifications with real time retrotranscription quantitative polymerase chain reaction (RTqPCR) have been done in all these models. For instance, in the emblematic model of replicative senescence of WI-38 human fibroblasts, comparison was also possible with many data previously found by other technologies like Northern blots or high density DNA arrays by many independent laboratories (DebacqChainiaux et al., 2008).

We report the identification of age-related transcriptomic biomarkers in total RNA of PBMC of old blood donors compared to young counter parts.

\section{Materials and methods}

\subsection{Population recruitment}

The recruitment was conducted at the University Hospital of Mont-Godinne (UCL, Belgium). We considered two groups: young to middle-age healthy volunteers and aged healthy volunteers. Young to middle-age participants were recruited on a voluntary basis among the staff of the hospital upon general announcement. The age of the young to middle-age volunteers ranged between 25 and 48 years old. All were clinically symptom-free. Healthy aged participants were recruited on a voluntary basis from different senior associations. To be eligible, participants needed (1) to be aged 75 years and over; (2) not to be institutionalized; (3) to have no evidence of an acute medical condition, nor deterioration of a chronic condition in the previous month. Exclusion criteria were the use of steroidal or non-steroidal anti-inflammatory drugs 1 week before the inclusion, cancer or cancer history, and haematological disease. The ethics committee of the hospital approved the study.

\subsection{Isolation of $P B M C$ and $R N A$ expression}

PBMCs were isolated from $16 \mathrm{~mL}$ of whole blood by centrifugation through Ficoll-Hypaque gradient centrifugation (BectonDickinson Vacutainer CPT, USA) and were washed twice in HBSS buffer. After adjustment at $10^{8}$ cells $/ \mathrm{mL}$, part of the suspension were dispatched for hemogram determination (ADVIA 120, Baker, USA) while the rest were used for total RNA extraction (Total RNAgents $^{\circledR}$ Total RNA Isolation System, Promega, USA) according to the manufacturer's protocol and stored at $-80^{\circ} \mathrm{C}$.

The quality of total RNA samples was assessed (Agilent 2100 Bioanalyzer, Agilent Technologies, Germany). Reverse transcription, RNA amplification and labelling using the MessageAmp ${ }^{\mathrm{TM}}$ II-Biotin Enhanced kit (Ambion, USA) were performed from $250 \mathrm{ng}$ of total RNA.

\subsection{Low-density DNA-array analysis}

\subsubsection{Design of the array}

We purchased a low-density DNA array on-demand able to detect 148 different transcripts species (Eppendorf, Germany) involved in immunosenescence, and more specifically focusing the T-cell compartment. Transcripts involved in stress response and cell senescence was also considered as described in the introduction.

The method is based on a system with two assays per glass side with three identical sub-arrays per assay. The sequences of the DNA covalently linked to the glass slide were carefully chosen by sequence comparison. Checks were made to ensure that no cross-hybridization takes place. Several positive and negative hybridization controls plus detection controls were spotted on the array in order to control the reliability of the experimental data.

\subsubsection{Hybridization and detection}

Hybridization on the array was carried out as described by the manufacturer using $15 \mu \mathrm{g}$ of complementary DNA (cDNA). The hybridization reaction was performed overnight at $60^{\circ} \mathrm{C}$ in a Thermoblock for DualChip ${ }^{\circledR}$ Slides used with a Thermomixer comfort (Eppendorf, Germany).

Detection was performed using a Cy3-conjugated IgG anti-biotin (Jackson Immuno Research Laboratories, USA). Fluorescence of the hybridized arrays was scanned using the Packard ScanArray (PerkinElmer, USA) at a resolution of $10 \mu \mathrm{m}$. To maximize the dynamic range of detection, the same arrays were scanned at three photomultiplier (PMT) gains for quantifying high- and low-copy expressed genes. The scanned 16-bit images were imported into the ImaGene 4.1 software (BioDiscovery, USA). The fluorescence intensity of each DNA spot (median intensity of each pixel present within the spot) was calculated using local median background subtraction. Intensity values from high-PMT-gain pictures were used, except in the case of saturated spots. In the latter case, intensity values from intermediate PMT-gain pictures (or from low PMT-gain pictures in case of spots also saturated in the intermediate PMT-gain pictures) were used after scale correction. Only spots with median intensity after background subtraction at least twofold higher than their local background were taken into account. The median of the three intensity values of the triplicate DNA spots was used in further steps.

\subsection{Data normalization and inter-batch correction}

All micro-arrays results were normalized against a single reference applying a local weighted regression (Smyth et al., 2003). The micro-array was provided by Eppendorf in three batches. The systematic intensity bias detected between the production batches was corrected successfully. Four samples were hybridized four times onto arrays of the three different batches. For each spotted sequence, a correction factor between the first batch and each of the others was computed using these four samples. This spot and batch dependent correction factor was applied to normalize intensities of each array. These normalized and corrected intensities were used in further statistical analyses.

\section{5. $R T-q P C R$}

First-strand cDNA was synthesized from $1 \mu \mathrm{g}$ of total RNA, in a $20 \mu \mathrm{L}$ reaction mix, using $200 \mathrm{U}$ Superscript II reverse transcriptase in the presence of $1 \mu \mathrm{g}$ of oligo(dT) (Invitrogen, UK). The expression of five genes was assessed using qPCR (sequence of the primers: Table 1). Amplification reaction assays were performed in $25 \mu \mathrm{L}$ total volume containing $12.5 \mu \mathrm{L}$ of Sybr Green PCR Mastermix, $2.5 \mu \mathrm{L}$ of each primer at $300 \mathrm{mM}$ final concentrations and $5 \mu \mathrm{L}$ of 1000 -dilution of cDNA. qPCRs without cDNA were performed as template-free negative controls. qPCR were performed in duplicates with a hot start at $95^{\circ} \mathrm{C}$ for 5 min followed by $40 \mathrm{cy}-$ cles at $95^{\circ} \mathrm{C}$ for $15 \mathrm{~s}$ and $65^{\circ} \mathrm{C}$ for 1 min using the 7000 SDS thermal cycler (Applied Biosystems, The Netherlands). Melting curves were generated after amplification. Fluorescence emission was 
Table 1

Primer sets used in RT-qPCR. Primers were designed based on the original probe location with the Primer3 program.

\begin{tabular}{lll}
\hline Gene & Forward & Reverse \\
\hline RPS9 & CTGGATGAGGGCAAGATGAAG & GTCTGCAGGCGTCTCTCTAAGAA \\
BCL2 & AGATACTGAGTAAATCCATGCACCTAAAC & CCACTGTCACTCTTGCAAATTCTAC \\
CD69 & GGAAATCTGTGTCAGTGGATGCT & GTGCAGATTTCCTGGAATTCTT \\
CLU & GGA TGA AGG ACC AGT GTG ACA AG & CAG CGA CCT GGA GGG ATT C \\
CTSD & GATGAGCTGGAAGGAGTGAGAG & CCACCTCCAGGCCAATACAT \\
IL1R1 & TTAAAGATGCCTAAGTGTTGAAGA & GGCTCAATACCTTTTATTCAAATAAG
\end{tabular}

detected for each PCR cycle and the threshold cycle values $\left(C_{\mathrm{t}}\right)$ were determined using the thermal cycler software. For each experiment and each gene the efficiency of the qPCR was assessed with three dilution factors $(100 ; 1000$ and 10,000) of one cDNA sample. The RPS9 gene was used as a house keeping gene in order to compare gene expression between samples. This gene is selected for its expression constant in all the tested samples. The expression ratio of one gene $g$ between two samples $A$ and $B$ was computed as following: $\frac{E_{g}^{C_{g}, B}}{E_{\mathrm{r}, B}} \times \frac{E_{\mathrm{r}}^{C_{\mathrm{r}}, \mathrm{A}}}{E_{\mathrm{g}, \mathrm{A}}}$ where $E_{\mathrm{g}}$ and $E_{\mathrm{r}}$ are efficiencies of qPCR for genes $g$ and RPS9, $C_{\mathrm{g}, \mathrm{A}}, C_{\mathrm{g}, \mathrm{B}}, C_{\mathrm{r}, \mathrm{A}}$ and $C_{\mathrm{r}, \mathrm{B}}$ are the $C_{\mathrm{t}}$ of genes $\mathrm{g}$ and RPS9 in samples A and B.

\subsection{Statistical analyses}

The Mann-Whitney test was used to compare the difference of mRNA abundances between two groups. We used $p$-value with the Benjamini correction ( $p$-value $\times m / g$, where $m$ is the number of variables and $g$ the rank of the variable according to $p$-value). The correlation between micro-array and RT-qPCR results was performed using a Pearson correlation analysis.

\section{Results}

We designed a specific low-density DNA array for studying mRNA abundance of gene involved in T-cell senescence, cell senescence in general and stress response. We explained in the introduction how this list of transcripts was designed. This list is available as Supplementary material (Table S1).

\subsection{Mean age of the probands}

RNA was isolated from PBMC of 25 young to middle-age healthy volunteers ( 14 women and 11 men, 25-48 years old, mean age $35.0 \pm 6.5$; mean $\pm S D$ ), and 23 aged healthy volunteers ( 12 women and 11 men, $75-103$ years old, mean age $82.5 \pm 6.8$; mean $\pm S D$ ) subjects. The two groups were matched for gender. The health status of the probands was determined as explained in Section 2.

\subsection{Micro-array result validation}

More than 100 verifications of data obtained in bioregontological studies with a similar array have already been done using RTqPCR. However, the results obtained herein on a random selection of five transcripts among our list of transcripts were used to assess the quality of micro-assay measurements using RT-qPCR. Fourteen independent samples from blood of different persons were analysed both with the array and with RT-qPCR. The comparison between RT-qPCR cycle threshold normalized and micro-array $\log 2$ ratio value using a Pearson correlation analysis yielded a $p$-value of 0.001 . The coefficient correlation was 0.94 , indicating that the micro-array results were significantly correlated with the RT-qPCR values (Fig. 1). The amplitudes of the expression ratio logarithms resulting from the RT-qPCR are generally slightly higher, as reported previously. The difference can be explained by a greater

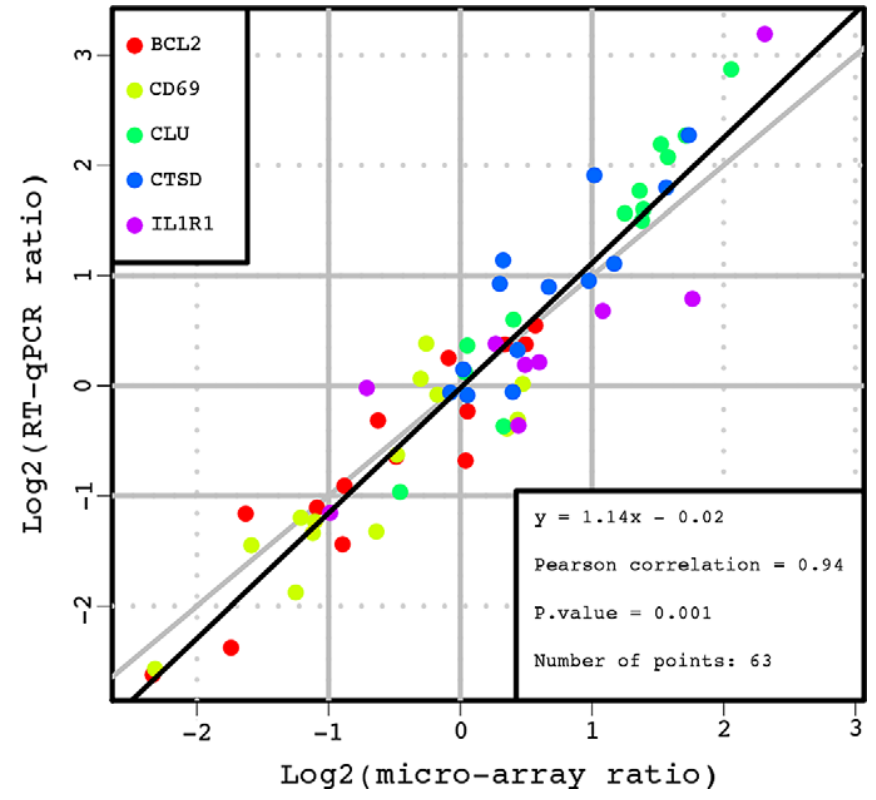

Fig. 1. Comparison of the gene expression ratios obtained by RT-qPCR and microarrays. Grey vertical lines are expression ratios logarithms equal to $-1,0$ and 1 . Grey diagonal line is the graphic bisector $(y=x)$. Black diagonal line is the regression line calculated with data corresponding to 63 dots represented. The line equation is indicated with the Pearson correlation coefficient and the associated $p$ value.

sensitivity of the RT-qPCR due to exponential amplification of the signal (Borlon et al., 2008a,b; Debacq-Chainiaux et al., 2005, 2008).

\subsection{Identification of differentially abundant transcripts}

From a total of 148 transcript species including those of 13 housekeeping genes, 77 transcript species were detected in the samples of PBMC of all the subjects, 71 transcript species were either not detectable in any of the subjects or not quantifiable. Thus 77 detected transcript species were selected as eligible for further analyses. There was no situation where a transcript was detected in a condition and not detected in the other.

We did no observe any significant differences of the abundance of each transcript between men and women in each age group of probands. To elucidate differences of the abundance of PBMC transcripts between young to middle-age and aged healthy participants, mRNA level was analysed individually for the 77 detected transcripts using a Mann-Whitney test, with a Benjamini and Hochberg false-discovery rate, and a $p$-value $\leqslant 0.05$. This resulted in a list of 16 differentially abundant transcripts. From these 16 transcripts, 11 were more abundant and five were less abundant in the PBMC of the elderly subjects. The list of these transcripts and a heat map are shown in Table 2 and Fig. 2, respectively.

\subsection{Age-associated differential expression of genes in PBMC}

The transcripts differentially abundant in PBMC of aged versus young to middle-age subjects, might be potential markers of 
Table 2

Genes differentially expressed in PMBC of old healthy probands $(n=23)$ versus young to middle-age healthy probands ( $n=25)$. Statistical analysis was carried out with the Mann-Whitney test.

\begin{tabular}{|c|c|c|c|c|c|}
\hline $\begin{array}{l}\text { Official gene } \\
\text { symbol }\end{array}$ & Gene name (according to HUGO database and Entrez gene) & $\begin{array}{l}\text { Accession } \\
\text { number }\end{array}$ & $\begin{array}{l}\text { Aged/young to middle- } \\
\text { age }\end{array}$ & $p$-Value & Benjamini \\
\hline HSPA6 & Heat shock 70-kDa protein 6 (HSP70B') & NM_002155.1 & 1.83 & $1.62 \mathrm{E}-04$ & $1.59 \mathrm{E}-03$ \\
\hline TNFRSF1A & Tumor necrosis factor receptor superfamily, member $1 \mathrm{~A}$ & NM_001065.2 & 1.68 & $3.17 \mathrm{E}-05$ & $3.74 \mathrm{E}-04$ \\
\hline HMOX1 & Heme oxygenase (decycling) 1 & NM_002133.1 & 1.46 & $1.62 \mathrm{E}-05$ & $3.19 \mathrm{E}-04$ \\
\hline GAA & $\begin{array}{l}\text { Glucosidase, alpha; acid (Pompe disease, glycogen storage } \\
\text { disease type II) }\end{array}$ & NM_000152.2 & 1.45 & $3.10 \mathrm{E}-04$ & $2.49 \mathrm{E}-03$ \\
\hline $\mathrm{CTSH}$ & Cathepsin $\mathrm{H}$ & NM_004390.1 & 1.38 & $2.84 \mathrm{E}-05$ & $3.87 \mathrm{E}-04$ \\
\hline CTSD & Cathepsin D (lysosomal aspartyl peptidase) & M11233.1 & 1.37 & $3.38 \mathrm{E}-06$ & $1.20 \mathrm{E}-04$ \\
\hline CTSS & Cathepsin S & M90696.1 & 1.34 & $3.35 \mathrm{E}-08$ & $1.48 \mathrm{E}-06$ \\
\hline TNFRSF1B & Tumor necrosis factor receptor superfamily, member $1 \mathrm{~B}$ & NM_001066.1 & 1.26 & $7.41 \mathrm{E}-03$ & $3.54 \mathrm{E}-02$ \\
\hline TUBA1B & Tubulin, alpha $1 \mathrm{~b}$ & NM_006082 & 1.23 & $3.84 \mathrm{E}-06$ & $1.13 \mathrm{E}-04$ \\
\hline EIF4A1 & Eukaryotic translation initiation factor $4 \mathrm{~A}$, isoform 1 & NM_001416.1 & 1.22 & $6.31 \mathrm{E}-06$ & $1.60 \mathrm{E}-04$ \\
\hline CD86 & CD86 antigen (CD28 antigen ligand 2, B7-2 antigen) & NM_006889.1 & 1.22 & $9.59 \mathrm{E}-03$ & $4.14 \mathrm{E}-02$ \\
\hline MAX & MYC associated factor $\mathrm{X}$ & NM_002382.2 & 0.78 & $2.04 \mathrm{E}-05$ & $3.00 \mathrm{E}-04$ \\
\hline PRDX6 & Peroxiredoxin 6 & NM_004905.1 & 0.77 & $1.82 \mathrm{E}-05$ & $3.22 \mathrm{E}-04$ \\
\hline LCK & Lymphocyte-specific protein tyrosine kinase & NM_005356.2 & 0.77 & $4.43 \mathrm{E}-04$ & $3.41 \mathrm{E}-03$ \\
\hline $\mathrm{CD} 28$ & CD28 antigen $(\mathrm{Tp} 44)$ & NM_006139.1 & 0.62 & $1.93 \mathrm{E}-03$ & $1.14 \mathrm{E}-02$ \\
\hline CD69 & CD69 antigen (p60, early T-cell activation antigen) & NM_001781.1 & 0.70 & $7.41 \mathrm{E}-03$ & $3.75 \mathrm{E}-02$ \\
\hline
\end{tabular}

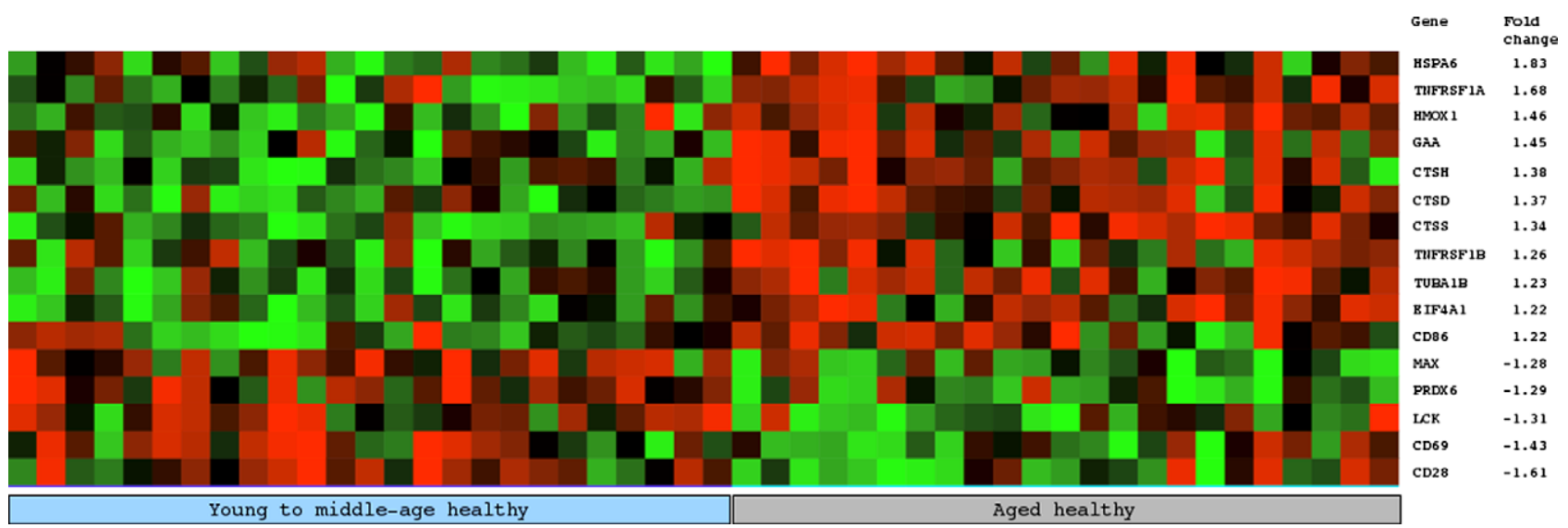

Fig. 2. Clustered heat map of the most significantly differentially expressed genes in the PBMC between aged healthy and young to middle-age healthy probands. Differences in the levels of mRNA abundance are represented by intensity of color with red representing higher and green for lower abundance. The expression profiles show a significant difference between the aged healthy and the young to middle-age healthy groups. Gene symbols for each probe are listed under "gene", $p$-values are from a Mann-Whitney test with a Benjamini and Hochberg false discovery threshold on 0.05 . Fold change is calculated from the mean log ratio of aged versus young to middle-age.

healthy ageing. Most of these transcripts differentially expressed in aged and young to middle-age groups can be sorted according to their variation with ageing. The transcripts less abundant with age were: CD28, CD69, LCK, PRDX6 and MAX. Transcripts more abundant in the aged group include $\mathbb{C D} 86, C T S D, C T S H, C T S S, E I F 4 A 1$, GAA, HMOX1, HSPA6, TNFRSF1A, TNFRSF1B and TUBA1B. The most important variations observed were increased abundance of HSPA6 and TNFRSF1A, respectively, 1.83 - and 1.68 -fold, and the decreased abundance of $C D 28$ and $C D 69$, respectively, 1.61- and 1.43-fold, in the aged group compared to the young group (Table 2 and Fig. 2). However, we have currently no available data to evaluate the abundance of the corresponding proteins.

\section{Discussion}

Ageing is associated with a myriad of changes in all the organs of our body. Ageing is a continuous process that affects individuals from maturity to old age, first gradually from 20 to 65 years old in humans. Abrupt changes are observed in healthy individuals over 75 years old (Faria et al., 2008).

In this work, we searched for transcriptional markers of human ageing in the total RNA of PBMC isolated from young to middle-age healthy (25-48 years old) and aged healthy (75-103 years old) probands. The study design was to select a limited panel of transcript species and to measure their abundance in PBMC samples from subjects expected to be in a sufficient number to reach statistical significances. The selected panel contained transcripts involved in the cellular mechanism of senescence, stress response as well as specific transcripts previously proposed to be involved in immunosenescence (Franceschi et al., 1999; Pawelec et al., 1999). The comparison of data from young to middle-age and old probands showed a similar transcript abundance for about $79 \%$ of the transcripts while $21 \%$ displayed an altered abundant level in a total of 77 transcripts significantly above the detection limit.

The majority of the differential abundance is relevant to the immune system. Interestingly, this transcriptional view of immunosenescence can be linked to observed deficits and modifications of the immune system of old humans. The decreased abundance of CD28 and LCK mRNA in aged healthy is reflected at the protein level (Boucher et al., 1998; Vallejo, 2005). Both molecules indicate TCR signaling pathways modification occurring with ageing. Interaction of the TCR with an antigen induces a rapid early cascade of intracellular signaling events that leads to T-cell activation. Nevertheless, the binding of TCR to antigen alone is insufficient to drive immune reaction. Activation requires co-stimulation with CD28, a 
membrane glycoprotein, which plays multiple roles such as amplifying the cytokine production or insuring a complete and efficient T-cell activation (Nel, 2002; Riley and June, 2005). TCR engagement recruits LCK and FYN, protein kinases initiating the TCR signaling pathway (Salmond et al., 2009). Unlike LCK, expression of FYN was not affected by ageing in our study (data not shown). Decreased abundance of CD28 and LCK mRNA indicates that early signaling events following antigen stimulation are altered with ageing in T lymphocytes. This hypothesis of lowered activation was reinforced by the $30 \%$ decrease of the mRNA level of early activation surface markers CD69 found in comparison to young to middleage subjects (Table 2 and Fig. 2). The changes at the mRNA level positively correlate with biochemical and cytometric observations (Boucher et al., 1998; Fulop et al., 1999; Lio et al., 1996). These agerelated variations in the T-cell activation mechanisms probably explain the lower efficiency of vaccination procedure in old persons, where TCR antigen recognition and T-cell activation are primary phenomenon involved as well as higher infectious risk when involving adaptive immune system.

Interestingly, the ligand of CD28 is a heterodimer formed by CD80 and CD86 present on many cell types with an antigen presenting cell (APC) activity (Lindsten et al., 1993; Salomon and Bluestone, 2001; Thompson et al., 1989). Up-regulation of CD80 in older adult monocytes by Toll-like receptor signaling was recently shown to be less effective while more complex regulation of CD86, which involves a secondary down-regulation by interleukin-10 (IL10 ), also seems to be impaired in old subjects (van Duin et al., 2007). Nevertheless, a closer look at the dendritic cells from aged subjects revealed that both their CD80 and CD86 can be more efficiently up-regulated by self-antigen than in young subjects (Agrawal et al., 2009). We observed that, in healthy elderly, the basal level of expression of CD86 was 22\% higher than in the young to middle-age group with no significant change in CD80. This higher level of CD86 could be related to the pro-inflammatory cytokine profile observed in the elderly subjects (Fagiolo et al., 1993). The CD86 down regulator IL-10 (Lim et al., 2002) was not evidenced significantly differences between healthy young and old probands (not shown). This suggests that the age-related potent increased co-stimulatory activity of APC is due to the elevated concentration of pro-inflammatory cytokines, which is counterbalanced by a reduced expression of CD28 receptor that could in the end lead to hypo-responsiveness of T-cell response.

Further involvement of ageing in the mechanism of antigen presentation is strongly suggested by a series of lysosomal proteases, which mRNA is more abundant in the elderly group. The Cathepsin genes CTSD, CTSH and CTSS all code for lysosomal proteases involved in physiological protein degradation (Kirschke and Wiederanders, 1987). Cathepsins are constitutively expressed in all known professional APCs and are believed to play role in antigen processing (Chapman, 2006). This has been clearly demonstrated for Cathepsin S (CTSS), which degrades the invariant peptide chain associated with the exogenous peptide presenting molecule MHC class II (Gupta et al., 2008; Maubach et al., 2007). CTSS also generates peptides for the vacuolar pathway of antigen presentation in vivo (Beers et al., 2005; Shen and Rock, 2004), whereas the role of Cathepsin D (CTSD) and Cathepsin H (CTSH) in presented antigen generation are still to confirm, as discrepancies appeared according to the model used (Deussing et al., 1998; Hewitt et al., 1997; Villadangos et al., 1997). From a clinical point of view, higher expression of CTSH has been correlated with malignant progression of prostate tumors (Waghray et al., 2002) and other cancers (Dan et al., 2003). As for CD86, it has been shown that interferon- $\gamma($ IFN- $\gamma$ ) increases the expression level of CTSS (Maubach et al., 2007), which is coherent with the idea that the pro-inflammatory cytokine profile of old subjects stimulates the antigen presentation processing.
The plausible consequences of increased pro-inflammatory cytokine profile of old persons are known. In this study, we observed an up-regulation of some of these cytokine receptors at the mRNA level. The TNFRSF1A and TNFRSF1B genes encode the type 1 (TNFR- 1 ), and type 2 (TNFR-2) receptors of TNF- $\alpha$, respectively, and exert their biological through distinct signaling pathways (Gupta et al., 2004). In addition to inflammatory cytokine induction, TNF- $\alpha$ can stimulate apoptosis, but also activates NF$\kappa \mathrm{B}$ transcription factor, which in turn activates transcription of genes that block TNF-induced cell death (Xiao et al., 2001, 2002). With ageing, both TNF- $\alpha$ production and TNF- $\alpha$-induced apoptosis are increased (Agarwal et al., 1999; Fagiolo et al., 1993). An increased expression of TNFRSF1A and a decreased expression of TNFRSF1B in lymphocytes from aged humans have been reported (Agarwal et al., 1999). These changes have been associated with increased apoptosis observed in aged lymphocytes, as it was suggested that TNFRSF1A pathway is more pro-apoptotic while TNFRSF1B pathway would preferentially induce the anti-apoptotic c-IAP1 and c-IAP2 proteins. In our study, however, both TNFRSF1A and TNFRSF1B are up-regulated in PBMC from aged humans. Our results, if confirmed at protein level by further studies, would be in contradiction with the hypothesis of an overall pro-apoptotic mechanism in aged T-cell and suggests that a balance might emerge between the two receptors, leading to a more subtle regulation of T-cell apoptosis.

Aside from the modifications observed in the abundance of transcripts directly involved in the immune system function, other transcripts displayed significantly modified abundance in the PBMC of the old probands.

Expression of GAA, EIF4A, MAX and TUBAI1B is altered in ageing with increased mRNA abundance of GAA, EIF4A and TUBAI1B transcripts and decreased abundance of MAX transcripts. The GAA gene encodes acid alpha-glucosidase, which is essential for the degradation of glycogen to glucose in lysosomes. The EIF4A1 gene is implied in the control of translation, and thus is involved in protein synthesis and cell proliferation (Flynn and Proud, 1996). The MAX gene encodes a protein of transcription regulator. The TUBAI1B gene encodes the tubulin, which is the major constituent of microtubules. These are potential interesting transcript markers in ageing.

Ageing is associated with progressively increased oxidative stress and damage, with potential changes of expression of genes involved in stress response. In this work, HMOX1 and HSPA6 mRNAs were found as more abundant in PBMC from elderly subjects, compared with PBMC from young to middle-age control subjects. HMOX1 gene encodes heme oxygenase, which is an essential enzyme associated with oxidative stress in many cell types such as fibroblasts (Pascal et al., 2007). HSPA6 is a member of the human heat-shock protein gene family, encoding a basic $70-\mathrm{kDa}$ protein (Leung et al., 1990). HMOX1 and HSPA6 mRNA levels are potential functional markers of ageing, probably due to their involvement in stress response (Calabrese et al., 2008; Chowdhury et al., 2009; Gong et al., 2004; Hori et al., 2002; Lee et al., 1996). HMOX1 activity and protein levels were increased in the liver with age (Abraham et al., 1985; Kang et al., 2005). As for HSPA6, it was reported that aged individuals of particular species develop a constitutively increased level of several chaperones, including HSP70 (Soti and Csermely, 2000). The finding that HMOX1 and HSPA6 transcript species increased in healthy old persons may be explained by compensatory induction of these genes to cope with increased oxidative stress and damage in ageing. We have no clue about the potential reasons for the decreased mRNA level of PRDX6 antioxidant enzyme.

Ageing is a multi-dimensional process. Age-related changes of gene expression contribute to the physiological alterations observed with ageing. This work provided a list of 16 transcripts dif- 
ferentially abundant in the PBMC of old healthy subjects, compared to subjects of young to middle-age. Even with the selection bias of gene selection and PBMC examination, changes of expression of immune response-related genes appears predominant in this study. Most of these changes can be related to modification of immune functions observed in aged healthy people. Thus, the transcriptomic changes identified herein should not be regarded only as biomarkers since these alterations might also have physiological consequences.

\section{Acknowledgements}

The authors thank all the patients included in this study for their participation. This work was supported by the Walloon Region of Belgium (DGTRE Reseaux 2-SENEGENE No. 05/1/6192). O. Toussaint and F. Debacq-Chainiaux are, respectively, Senior Research Associate and Research Associate of the FNRS Belgium.

\section{Appendix A. Supplementary data}

Supplementary data associated with this article can be found, in the online version, at doi:10.1016/j.exger.2009.12.001.

\section{References}

Abraham, N.G., Levere, R.D., Freedman, M.L., 1985. Effect of age on rat liver heme and drug metabolism. Exp. Gerontol. 20, 277-284.

Agarwal, S.K., Khatri, S., Anuradha, S., Singh, N.P., Baveja, U., 1999. Tumour necrosis factor-alpha and interleukin-2 in pus aspirate and blood in patients with amoebic liver abscess. J. Assoc. Physicians India 47, 1065-1067.

Agrawal, A., Tay, J., Ton, S., Agrawal, S., Gupta, S., 2009. Increased reactivity of dendritic cells from aged subjects to self-antigen, the human DNA. J. Immunol. $182,1138-1145$

Beers, C., Burich, A., Kleijmeer, M.J., Griffith, J.M., Wong, P., Rudensky, A.Y., 2005. Cathepsin S controls MHC class II-mediated antigen presentation by epithelial cells in vivo. J. Immunol. 174, 1205-1212.

Borlon, C., Vankoningsloo, S., Godard, P., Debacq-Chainiaux, F., Toussaint, O., 2008a. Identification of p53-dependent genes potentially involved in UVB-mediated premature senescence of human skin fibroblasts using siRNA technology. Mech. Ageing Dev. 129, 109-119.

Borlon, C., Weemaels, G., Godard, P., Debacq-Chainiaux, F., Lemaire, P., Deroanne, C., Toussaint, O., 2008b. Expression profiling of senescent-associated genes in human dermis from young and old donors. Proof-of-concept study. Biogerontology 9, 197-208.

Boucher, N., Dufeu-Duchesne, T., Vicaut, E., Farge, D., Effros, R.B., Schachter, F., 1998. CD28 expression in T cell aging and human longevity. Exp. Gerontol. 33, 267282.

Calabrese, V., Cornelius, C., Mancuso, C., Pennisi, G., Calafato, S., Bellia, F., Bates, T.E. Giuffrida Stella, A.M., Schapira, T., Dinkova Kostova, A.T., Rizzarelli, E., 2008. Cellular stress response: a novel target for chemoprevention and nutritional neuroprotection in aging, neurodegenerative disorders and longevity. Neurochem. Res. 33, 2444-2471.

Chapman, H.A., 2006. Endosomal proteases in antigen presentation. Curr. Opin. Immunol. 18, 78-84

Chowdhury, I., Mo, Y., Gao, L., Kazi, A., Fisher, A.B., Feinstein, S.I., 2009. Oxidant stress stimulates expression of the human peroxiredoxin 6 gene by a transcriptional mechanism involving an antioxidant response element. Free Radic. Biol. Med. 46, 146-153.

Dan, S., Shirakawa, M., Mukai, Y., Yoshida, Y., Yamazaki, K., Kawaguchi, T., Matsuura, M., Nakamura, Y., Yamori, T., 2003. Identification of candidate predictive markers of anticancer drug sensitivity using a panel of human cancer cell lines. Cancer Sci. 94, 1074-1082.

de Longueville, F., Surry, D., Meneses-Lorente, G., Bertholet, V., Talbot, V., Evrard, S., Chandelier, N., Pike, A., Worboys, P., Rasson, J.P., et al., 2002. Gene expression profiling of drug metabolism and toxicology markers using a low-density DNA microarray. Biochem. Pharmacol. 64, 137-149.

de Magalhaes, J.P., Chainiaux, F, de Longueville, F., Mainfroid, V., Migeot, V., Marcq L., Remacle, J., Salmon, M., Toussaint, O., 2004. Gene expression and regulation in $\mathrm{H}_{2} \mathrm{O}_{2}$-induced premature senescence of human foreskin fibroblasts expressing or not telomerase. Exp. Gerontol. 39, 1379-1389.

Debacq-Chainiaux, F., Borlon, C. Pascal, T., Royer, V., Eliaers, F, Ninane, N., Carrard, G., Friguet, B., de Longueville, F., Boffe, S, et al., 2005. Repeated exposure of human skin fibroblasts to UVB at subcytotoxic level triggers premature senescence through the TGF-beta1 signaling pathway. J. Cell Sci. 118, 743-758.

Debacq-Chainiaux, F., Pascal, T., Boilan, E., Bastin, C., Bauwens, E., Toussaint, O., 2008. Screening of senescence-associated genes with specific DNA array reveals the role of IGFBP-3 in premature senescence of human diploid fibroblasts. Free Radic. Biol. Med. 44, 1817-1832.
Deussing, J., Roth, W., Saftig, P., Peters, C., Ploegh, H.L., Villadangos, J.A., 1998. Cathepsins B and D are dispensable for major histocompatibility complex class II-mediated antigen presentation. Proc. Natl. Acad. Sci. USA 95, 4516-4521.

Fagiolo, U., Cossarizza, A., Scala, E., Fanales-Belasio, E., Ortolani, C., Cozzi, E., Monti, D., Franceschi, C., Paganelli, R., 1993. Increased cytokine production in mononuclear cells of healthy elderly people. Eur. J. Immunol. 23, 2375-2378.

Faria, A.M. de Moraes, S.M. de Freitas, L.H. Speziali, E, Soares, T.F, FigueiredoNeves, S.P., Vitelli-Avelar, D.M., Martins, M.A., Barbosa, K.V., Soares, E.B., et al., 2008. Variation rhythms of lymphocyte subsets during healthy aging. Neuroimmunomodulation 15, 365-379.

Farooqui, T., Farooqui, A.A., 2009. Aging: an important factor for the pathogenesis of neurodegenerative diseases. Mech. Ageing Dev. 130, 203-215.

Flynn, A., Proud, C.G., 1996. The role of eIF4 in cell proliferation. Cancer Surv. 27, 293-310.

Franceschi, C., Valensin, S., Fagnoni, F., Barbi, C., Bonafe, M., 1999. Biomarkers of immunosenescence within an evolutionary perspective: the challenge of heterogeneity and the role of antigenic load. Exp. Gerontol. 34, 911-921.

Fulop Jr., T., Gagne, D., Goulet, A.C., Desgeorges, S., Lacombe, G., Arcand, M., Dupuis, G., 1999. Age-related impairment of p56lck and ZAP-70 activities in human T lymphocytes activated through the TcR/CD3 complex. Exp. Gerontol. 34, 197216.

Galvin, J.E., Ginsberg, S.D., 2005. Expression profiling in the aging brain: a perspective. Ageing Res. Rev. 4, 529-547.

Gillet, J.P., Efferth, T., Steinbach, D., Hamels, J., de Longueville, F., Bertholet, V., Remacle, J., 2004. Microarray-based detection of multidrug resistance in human tumor cells by expression profiling of ATP-binding cassette transporter genes. Cancer Res. 64, 8987-8993.

Gong, P., Cederbaum, A.I., Nieto, N., 2004. Heme oxygenase-1 protects HepG2 cells against cytochrome P450 2E1-dependent toxicity. Free Radic. Biol. Med. 36, 307-318.

Gupta, S., Hopner, S., Rupp, B., Gunther, S., Dickhaut, K., Agarwal, N., Cardoso, M.C., Kuhne, R., Wiesmuller, K.H., Jung, G., et al., 2008. Anchor side chains of short peptide fragments trigger ligand-exchange of class II MHC molecules. PLoS ONE 3, e1814.

Gupta, S., Kim, C., Yel, L., Gollapudi, S., 2004. A role of fas-associated death domain (FADD) in increased apoptosis in aged humans. J. Clin. Immunol. $24,24-29$.

Hewitt, E.W., Treumann, A., Morrice, N., Tatnell, P.J., Kay, J., Watts, C., 1997. Natural processing sites for human cathepsin $\mathrm{E}$ and cathepsin $\mathrm{D}$ in tetanus toxin: implications for T cell epitope generation. J. Immunol. 159, 4693-4699.

Hori, R., Kashiba, M., Toma, T., Yachie, A., Goda, N., Makino, N., Soejima, A., Nagasawa, T., Nakabayashi, K., Suematsu, M., 2002. Gene transfection of H25A mutant heme oxygenase- 1 protects cells against hydroperoxide-induced cytotoxicity. J. Biol. Chem. 277, 10712-10718.

Huppert, F.A. Solomou, W., O'Connor, S., Morgan, K., Sussams, P., Brayne, C., 1998. Aging and lymphocyte subpopulations: whole-blood analysis of immune markers in a large population sample of healthy elderly individuals. Exp. Gerontol. 33, 593-600.

Kang, M.J., Kim, H.J., Kim, H.K Lee, J.Y, Kim, D.H. Jung KJ., Kim, K.W., Baik, H.S., Yoo, M.A., Yu, B.P., Chung, H.Y., 2005. The effect of age and calorie restriction on HIF-1-responsive genes in aged liver. Biogerontology 6, 27-37.

Kirschke, H., Wiederanders, B., 1987. Lysosomal proteinases. Acta Histochem. 82, 2-

Lee, PJ., Alam, J. Wiegand, G.W., Choi, A.M. 1996. Overexpression of heme oxygenase- 1 in human pulmonary epithelial cells results in cell growth arrest and increased resistance to hyperoxia. Proc. Natl. Acad. Sci. USA 93, 1039310398.

Leung, T.K., Rajendran, M.Y., Monfries, C., Hall, C., Lim, L., 1990. The human heatshock protein family. Expression of a novel heat-inducible HSP70 (HSP70B') and isolation of its cDNA and genomic DNA. Biochem. J. 267, 125-132.

Lim, W., Ma, W., Gee, K., Aucoin, S., Nandan, D., Diaz-Mitoma, F., Kozlowski, M., Kumar, A., 2002. Distinct role of p38 and c-Jun N-terminal kinases in IL-10dependent and IL-10-independent regulation of the costimulatory molecule B7.2 in lipopolysaccharide-stimulated human monocytic cells. J. Immunol. 168, 1759-1769.

Lindsten, T., Lee, K.P., Harris, E.S., Petryniak, B., Craighead, N., Reynolds, P.J., Lombard, D.B., Freeman, G.J., Nadler, L.M., Gray, G.S., et al., 1993. Characterization of CTLA-4 structure and expression on human T cells. J. Immunol. 151, 3489-3499.

Lio, D., Candore, G., Cigna, D., D’Anna, C., Di Lorenzo, G., Giordano, C., Lucania, G., Mansueto, P., Melluso, M., Modica, M.A., Caruso, C., 1996. In vitro T cell activation in elderly individuals: failure in CD69 and CD71 expression. Mech. Ageing Dev. 89, 51-58.

Maubach, G., Lim, M.C., Kumar, S., Zhuo, L., 2007. Expression and upregulation of cathepsin $S$ and other early molecules required for antigen presentation in activated hepatic stellate cells upon IFN-gamma treatment. Biochim. Biophys. Acta $1773,219-231$.

Nel, A.E., 2002. T-cell activation through the antigen receptor. Part 1: Signaling components, signaling pathways, and signal integration at the T-cell antigen receptor synapse. J. Allergy Clin. Immunol. 109, 758-770.

Pascal, T., Debacq-Chainiaux, F., Boilan, E., Ninane, N., Raes, M., Toussaint, O., 2007. Heme oxygenase- 1 and interleukin-11 are overexpressed in stress-induced premature senescence of human WI-38 fibroblasts induced by tertbutylhydroperoxide and ethanol. Biogerontology 8, 409-422.

Pascal, T., Debacq-Chainiaux, F., Chretien, A., Bastin, C., Dabee, A.F., Bertholet, V., Remacle, J., Toussaint, O., 2005. Comparison of replicative senescence and 
stress-induced premature senescence combining differential display and lowdensity DNA arrays. FEBS Lett. 579, 3651-3659.

Patterson, T.A., Lobenhofer, E.K., Fulmer-Smentek, S.B., Collins, P.J., Chu, T.M. Bao, W., Fang, H., Kawasaki, E.S., Hager, J., Tikhonova, I.R., et al., 2006. Performance comparison of one-color and two-color platforms within the MicroArray Quality Control (MAQC) project. Nat. Biotechnol. 24, 11401150.

Pawelec, G., Effros, R.B., Caruso, C., Remarque, E., Barnett, Y., Solana, R., 1999. T cells and aging (update February 1999). Front. Biosci. 4, D216-D269.

Plackett, T.P., Boehmer, E.D., Faunce, D.E., Kovacs, E.J., 2004. Aging and innate immune cells. J. Leukoc. Biol. 76, 291-299.

Riley, J.L., June, C.H., 2005. The CD28 family: a T-cell rheostat for therapeutic control of T-cell activation. Blood 105, 13-21.

Salmond, R.J., Filby, A., Qureshi, I., Caserta, S., Zamoyska, R., 2009. T-cell receptor proximal signaling via the Src-family kinases, Lck and Fyn, influences T-cell activation, differentiation, and tolerance. Immunol. Rev. 228, 9-22.

Salomon, B., Bluestone, J.A., 2001. Complexities of CD28/B7: CTLA-4 costimulatory pathways in autoimmunity and transplantation. Annu Rev Immunol 19, 225252.

Shen, L., Rock, K.L., 2004. Cellular protein is the source of cross-priming antigen in vivo. Proc. Natl. Acad. Sci. USA 101, 3035-3040.

Shi, L., Reid, L.H., Jones, W.D., Shippy, R., Warrington, J.A., Baker, S.C., Collins, P.J., de Longueville, F., Kawasaki, E.S., Lee, K.Y., et al., 2006. The MicroArray Quality Control (MAQC) project shows inter- and intraplatform reproducibility of gene expression measurements. Nat. Biotechnol. 24, 1151-1161.

Smyth, G.K., Yang, Y.H., Speed, T., 2003. Statistical issues in cDNA microarray data analysis. Methods Mol Biol 224, 111-136.

Soti, C., Csermely, P., 2000. Molecular chaperones and the aging process. Biogerontology 1, 225-233.

Thoman, M.L., Weigle, W.O., 1989. The cellular and subcellular bases of immunosenescence. Adv Immunol 46, 221-261.

Thompson, C.B., Lindsten, T., Ledbetter, J.A., Kunkel, S.L., Young, H.A., Emerson, S.G., Leiden, J.M., June, C.H., 1989. CD28 activation pathway regulates the production of multiple T-cell-derived lymphokines/cytokines. Proc. Natl. Acad. Sci. USA 86, $1333-1337$.

Vallejo, A.N., 2005. CD28 extinction in human T cells: altered functions and the program of T-cell senescence. Immunol. Rev. 205, 158-169.

van Duin, D., Allore, H.G., Mohanty, S., Ginter, S., Newman, F.K., Belshe, R.B., Medzhitov, R., Shaw, A.C., 2007. Prevaccine determination of the expression of costimulatory B7 molecules in activated monocytes predicts influenza vaccine responses in young and older adults. J. Infect. Dis. 195, 1590-1597.

Vankoningsloo, S., De Pauw, A., Houbion, A., Tejerina, S., Demazy, C., de Longueville, F., Bertholet, V., Renard, P., Remacle, J., Holvoet, P., et al., 2006. CREB activation induced by mitochondrial dysfunction triggers triglyceride accumulation in 3T3-L1 preadipocytes. J. Cell Sci. 119, 1266-1282.

Vasto, S., Candore, G., Balistreri, C.R., Caruso, M., Colonna-Romano, G., Grimaldi, M.P., Listi, F., Nuzzo, D., Lio, D., Caruso, C., 2007. Inflammatory networks in ageing, age-related diseases and longevity. Mech. Ageing Dev. 128, 83-91.

Villadangos, J.A., Riese, R.J., Peters, C., Chapman, H.A., Ploegh, H.L., 1997. Degradation of mouse invariant chain: roles of cathepsins S and D and the influence of major histocompatibility complex polymorphism. J. Exp. Med. 186, 549-560.

Waghray, A., Keppler, D., Sloane, B.F., Schuger, L., Chen, Y.Q., 2002. Analysis of a truncated form of cathepsin $\mathrm{H}$ in human prostate tumor cells. J. Biol. Chem. 277, 11533-11538.

Xiao, C., Yang, B.F., Asadi, N., Beguinot, F., Hao, C., 2002. Tumor necrosis factorrelated apoptosis-inducing ligand-induced death-inducing signaling complex and its modulation by c-FLIP and PED/PEA-15 in glioma cells. J. Biol. Chem. 277, 25020-25025.

Xiao, C.W., Ash, K., Tsang, B.K., 2001. Nuclear factor-kappaB-mediated X-linked inhibitor of apoptosis protein expression prevents rat granulosa cells from tumor necrosis factor alpha-induced apoptosis. Endocrinology 142, 557-563.

Zdanov, S., Debacq-Chainiaux, F., Remacle, J., Toussaint, O., 2006. Identification of p38MAPK-dependent genes with changed transcript abundance in $\mathrm{H}_{2} \mathrm{O}_{2}$ induced premature senescence of IMR-90 hTERT human fibroblasts. FEBS Lett. $580,6455-6463$. 